MS. EMILY J HOWELLS (Orcid ID : 0000-0001-7732-2372)

DR. BENJAMIN CC HUME (Orcid ID : 0000-0001-7753-3903)

Article type : Original Article

\title{
Corals in the hottest reefs in the world exhibit symbiont fidelity not flexibility
}

Running title: Symbiodiniaceae from the hottest reefs

\section{Authors:}

Emily J. Howells ${ }^{1,2}$, Andrew G. Bauman ${ }^{3}$, Grace O. Vaughan ${ }^{1}$, Benjamin C. C. Hume ${ }^{4}$, Christian R. Voolstra ${ }^{4,5}$, John A. Burt ${ }^{1}$

1 Center for Genomics and Systems Biology, New York University Abu Dhabi, Abu Dhabi, United Arab Emirates

2 Centre for Sustainable Ecosystem Solutions and School of Earth, Atmospheric and Life Sciences, University of Wollongong, Wollongong, New South Wales 2522, Australia

3 Experimental Marine Ecology Laboratory, Department of Biological Sciences, National University of Singapore, Singapore

4 Red Sea Research Center, Division of Biological and Environmental Sciences and Engineering, King Abdullah University of Science and Technology (KAUST), Thuwal, Saudi Arabia

5 Department of Biology, University of Konstanz, Konstanz, Germany

\section{Correspondence:}

This article has been accepted for publication and undergone full peer review but has not been through the copyediting, typesetting, pagination and proofreading process, which may lead to differences between this version and the Version of Record. Please cite this article as doi: $\underline{10.1111 / \mathrm{mec} .15372}$

This article is protected by copyright. All rights reserved 


\section{Emily J. Howells}

School of Earth, Atmospheric \& Life Sciences, Faculty of Science, Medicine and Health, University of Wollongong, NSW 2522, Australia

$+61422327194$

em.howells@gmail.com
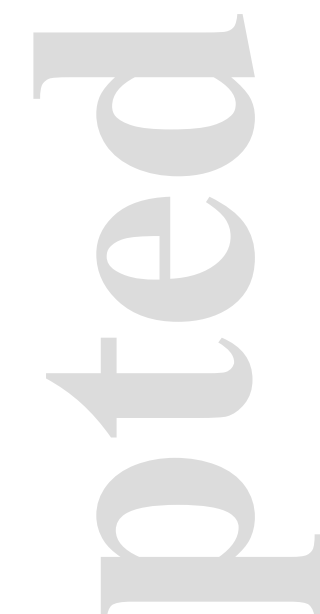

This article is protected by copyright. All rights reserved 


\section{Abstract}

3 Reef-building corals are at risk of extinction from ocean warming. While some corals can enhance

4 their thermal limits by associating with dinoflagellate photosymbionts of superior stress tolerance,

5 the extent to which symbiont communities will reorganise under increased warming pressure

6 remains unclear. Here we show that corals in the hottest reefs in the world in the Persian Gulf

7 maintain associations with the same symbionts across 1.5 -years despite extreme seasonal warming

8 and acute heat stress $\left(\geq 35^{\circ} \mathrm{C}\right)$. Persian Gulf corals predominantly associated with Cladocopium

9 (clade C) and most also hosted Symbiodinium (clade A) and/or Durusdinium (clade D). This is in

10 contrast to the neighbouring and milder Oman Sea, where corals associated with Durusdinium and

11 only a minority hosted background levels of Cladocopium. During acute heat stress, the higher

12 prevalence of Symbiodinium and Durusdinium in bleached versus non-bleached Persian Gulf

13 corals indicates that genotypes of these background genera did not confer bleaching resistance.

14 Within symbiont genera, the majority of ITS2 rDNA type profiles were unique to their respective

15 coral species, confirming the existence of host-specific symbiont lineages. Notably, further

16 differentiation among Persian Gulf sites demonstrates that symbiont populations are either isolated

17 or specialised over $10 \mathrm{~s}-100 \mathrm{~s}$ of $\mathrm{km}$. Thermal tolerance across coral species was associated with the

18 prevalence of a single ITS2 intragenomic sequence variant (C3gulf), definitive of the $C$.

19 thermophilum group. The abundance of $\mathrm{C} 3$ gulf was highest in bleaching resistant corals and at

20 warmer sites, potentially indicating a specific symbiont genotype (or set of genotypes) that may

21 play a role in thermal tolerance that warrants further investigation. Together, our findings indicate

22 that co-evolution of host-Symbiodiniaceae partnerships favours fidelity rather than flexibility in

23 extreme environments and under future warming.

\section{Introduction}

27 The evolutionary success of coral reefs is underpinned by productive symbioses between

28 scleractinian corals and members of the Symbiodiniaceae, which grow the living foundation of

29 these ecosystems. Symbiodiniaceae are single-celled dinoflagellates that densely pack the

30 gastrodermis of coral hosts, providing an essential source of energy (nutritional photosynthates,

31 (Muscatine, Falkowski, Porter, \& Dubinsky, 1984; Muscatine, McCloskey, \& Marian, 1981;

32 Whitehead \& Douglas, 2003) and enhancing skeletal growth rates (Cohen, Dubinsky, \& Erez, 
2016; Gattuso, Allemand, \& Frankignoulle, 1999). However, anomalously warm temperatures can

34 trigger a breakdown of this symbiosis (Weis, 2008), where corals become visually bleached from a

35 loss of their pigmented symbionts and become starved of energy (Porter, Fitt, Spero, Rogers, \&

36 White, 1989). Depending on stress severity and duration, bleached corals suffer complete or

37 partial mortality (e.g. Baird \& Marshall, 2002), or may recover with suppressed growth (e.g.

38 Goreau \& Macfarlane, 1990; Suzuki et al., 2003), reproduction (e.g. Howells, Ketchum, et al.,

39 2016; Szmant \& Gassman, 1990; Ward, Harrison, \& Hoegh-Guldberg, 2002), and/or disease

40 resistance (e.g. Lewis, Neely, Richardson, \& Rodriguez-Lanetty, 2017; Miller et al., 2009). Recent

41 heat waves have caused major losses of coral cover from all ocean basins (Ateweberhan,

42 McClanahan, Graham, \& Sheppard, 2011; Eakin et al., 2010; Hughes, Kerry, et al., 2018), and the

43 rapid rate of climate warming (up to $>3^{\circ} \mathrm{C}$ above preindustrial by 2100, (Collins et al., 2013)

44 threatens to outpace the capacity of corals to adapt (Hughes, Anderson, et al., 2018; Logan,

45 Dunne, Eakin, \& Donner, 2014).

46

47 Coral adaptation processes include genetic, epigenetic, and physiological responses in the coral

48 host, Symbiodiniaceae partners, and associated microbes (reviewed in Barshis, 2015; Morrow,

49 Muller, \& Lesser, 2018; Quigley, Baker, Coffroth, Willis, \& van Oppen, 2018; Torda et al., 2017).

50 As bleaching is typically initiated by oxidative damage to Symbiodiniaceae and/or host cells

51 (Oakley \& Davy, 2018), any enhancements to the heat tolerance of Symbiodiniaceae partners is

52 expected to confer bleaching resistance in the symbiosis. A diversity of Symbiodiniaceae taxa

53 from at least four genera (Symbiodinium, Breviolum, Cladocopium, Durusdinium; formerly,

54 Symbiodinium clades A-D; LaJeunesse et al., 2018) routinely associate with corals (reviewed in

55 Coffroth \& Santos, 2005). Heat tolerance varies widely among and within these genera (Swain,

56 Chandler, Backman, \& Marcelino, 2017; Tchernov et al., 2004), theoretically providing the

57 opportunity for corals to replace sensitive symbionts with more tolerant taxa (Buddemeier \&

58 Fautin, 1993). Indeed, Symbiodiniaceae communities within coral colonies can undergo dynamic

59 shifts in response to seasonal or acute temperature changes (Boulotte et al., 2016; Chen, Wang,

60 Fang, \& Yang, 2005; Jones, Berkelmans, van Oppen, Mieog, \& Sinclair, 2008), with demonstrated

61 increases to bleaching thresholds (Berkelmans \& van Oppen, 2006; Jones et al., 2008; Silverstein,

62 Cunning, \& Baker, 2015). However, colonies of several coral species exhibit no changes in their

63 Symbiodiniaceae communities during exposure to variable temperatures or bleaching stress

64 (McGinley et al., 2012; Stat, Loh, LaJeunesse, Hoegh-Guldberg, \& Carter, 2009; Thornhill,

This article is protected by copyright. All rights reserved 
65 LaJeunesse, Kemp, Fitt, \& Schmidt, 2006). These contradictory observations have been linked to 66 evolutionary differences among host and symbiont species in their capacity to associate with each 67 other (Aranda et al., 2016; Putnam, 2012), inferior nutrition from novel symbionts (Cantin, van 68 Oppen, Willis, Mieog, \& Negri, 2009; Cunning, Silverstein, \& Baker, 2015; Little, van Oppen, \& 69 Willis, 2004; Rädecker et al., 2018), and the environmental availability of Symbiodiniaceae 70 diversity (Cumbo, Baird, \& Van Oppen, 2013; Cunning, Yost, Guarinello, Putnam, \& Gates, 71 2015; Decelle et al., 2018). Alternatively, low taxonomic and quantitative resolution of early 72 molecular identification approaches may have prevented the detection of fine-scale changes in 73 Symbiodiniaceae communities (Boulotte et al., 2016; K. M. Quigley et al., 2014; Ziegler, Eguíluz, 74 Duarte, \& Voolstra, 2018), or the warming levels experienced by corals may not have been strong 75 enough to drive community changes.

77 In this study, we investigated the dynamics of Symbiodiniaceae communities of reef-building 78 corals in the northeastern Arabian Peninsula (Fig. 1). Corals in this region live in an extreme 79 environment and can thus serve as a study system to understand the fate of coral-symbiont 80 associations under future global warming scenarios. In particular, the southern Persian (Arabian) 81 Gulf is home to the hottest coral ecosystems in the world, where daily average summer seawater 82 temperatures are $>34-35^{\circ} \mathrm{C}$, and are lethal for corals elsewhere (Riegl, Purkis, Al-Cibahy, Abdel83 Moati, \& Hoegh-Guldberg, 2011). Gulf corals live exceptionally close to their upper thermal 84 limits (Howells, Abrego, Meyer, Kirk, \& Burt, 2016) and undergo repeated episodes of heat stress 85 (Riegl et al., 2018). They also experience large shifts in temperature across seasons $\left(\sim 16^{\circ} \mathrm{C}\right)$ and 86 hypersaline conditions (40-42 PSU; Bauman, Feary, Heron, Pratchett, \& Burt, 2013). Variation in 87 Symbiodiniaceae communities of common (Cyphastrea microphthalma and Platygyra daedalea)

88 and rare (Acropora downingi) corals was quantified by high-resolution next-generation sequencing 89 and profiling of the ITS2 rDNA marker (Hume et al., 2019). Communities were tracked in 90 individual coral colonies for up to 1.5 years encompassing seasonal temperature changes and a 91 coral bleaching event. We evaluated the effects of host identity, site, season, and bleaching 92 severity on the community composition of Symbiodiniaceae genera, ITS2 type profiles, and 93 sequences. 


\section{Materials and Methods}

\section{Collection of coral samples}

100

101 We characterised the community composition of endosymbiotic dinoflagellates (Family

102 Symbiodiniaceae) in reef-building corals that acquire their symbionts from the Persian Gulf and

103 Oman Sea environments. Individual colonies of Acropora downingi $(n=25)$, Cyphastrea

104 microphthalma $(n=53)$, and Platygyra daedalea $(n=50)$ were tagged at Delma $\left(24.5208^{\circ} \mathrm{N}\right.$, $\left.10552.2781^{\circ} \mathrm{E}\right)$, Saadiyat $\left(24.5986^{\circ} \mathrm{N}, 54.4201^{\circ} \mathrm{E}\right)$, Ras Ghanada $\left(24.8482^{\circ} \mathrm{N}, 54.6903^{\circ} \mathrm{E}\right)$, Dibba $106\left(25.6031^{\circ} \mathrm{N}, 56.3485^{\circ} \mathrm{E}\right)$, and $\mathrm{Al}$ Aqah $\left(25.4929^{\circ} \mathrm{N}, 56.3635^{\circ} \mathrm{E}\right.$; Fig. 1a). These five sites were 107 located at 4-7m depth and separated by 13-580 km (Fig. 1a). Within sites, colonies were located 108 along transects at uniform depth $(<1 \mathrm{~m}$ variation) and temperatures were recorded using loggers 109 attached to the reef substrate (HOBO pendant or TidbiT v2) (Fig. 1b). For each colony, $1-2 \mathrm{~cm}^{2}$ of 110 tissue from the upper central section was collected and preserved in $100 \%$ ethanol and 111 photographs were taken to provide visual health records.

112

113 All 128 colonies were first sampled in September 2012, at the end of an anomalously hot summer 114 in the Persian Gulf where water temperatures exceeded $35^{\circ} \mathrm{C}$ (Fig. 1b). At two of the study sites 115 (Saadiyat and Ras Ghanada) widespread coral bleaching was observed (see (Howells, Ketchum, et 116 al., 2016; Shuail et al., 2016), providing an opportunity to investigate the effect of bleaching 117 severity on Symbiodiniaceae community composition. Individual colonies were visually scored as 118 healthy (dark/normal pigmentation), moderately bleached (pale pigmentation), or severely 119 bleached (white pigmentation). In the aftermath of the bleaching, many A. downingi colonies died, 120 whereas all tagged colonies of $C$. microphthalma and $P$. daedalea survived. In recovering 121 colonies, egg numbers in the reproductive season following the bleaching event were quantified as 122 described in Howells, Ketchum, et al. (2016). This enabled us to evaluate whether 123 Symbiodiniaceae community composition during bleaching was associated with variation in the 124 reproductive output of surviving colonies. Subsets of the tagged colonies were resampled in April $1252013(n=116)$, September $2013(n=67)$, and February $2014(n=61)$. Combined with the initial 126 samples, this schedule followed the warmest and coolest months over two consecutive years, 127 which spanned annual ranges of $16^{\circ} \mathrm{C}$ for the Persian Gulf sites and $10-11^{\circ} \mathrm{C}$ for the Oman Sea 
128 sites (Fig. 1b). This allowed us to detect any changes in Symbiodiniaceae communities associated 129 with large seasonal changes in temperature.

130

131 Next-generation sequencing of Symbiodiniaceae endosymbionts

132

133 For each sample, a few $\mathrm{mm}^{3}$ of preserved tissue/skeleton were transferred to $750 \mu 1$ of DNA

134 extraction buffer (100 mM Tris/EDTA/NaCl, 1\% SDS) and incubated overnight at $65^{\circ} \mathrm{C}$. Proteins

135 were removed from chilled extracts (1 M potassium acetate), and DNA was precipitated (100\%

136 isopropanol), washed (70\% ethanol), re-suspended ( $0.1 \mathrm{M}$ Tris), and stored at $4{ }^{\circ} \mathrm{C}$. PCR

137 amplifications of the Symbiodiniaceae ITS2 rDNA region were performed following (Arif et al.,

138 2014). The primers ITSintfor2 and ITS2-reverse (LaJeunesse, 2002) were used with adapters

139 (underlined) for sequencing on the Illumina MiSeq platform: 5'-

140 TCGTCGGCAGCGTCAGATGTGTATAAGAGACAGGAATTGCAGAACTCCGTG-3'

141 (MiSeq-ITSintfor2) and 5'-

142 GTCTCGTGGGCTCGGAGATGTGTATAAGAGACAGGGGATCCATATGCTTAAGTTCAG

143 CGGGT-3' (MiSeq-ITS2-reverse). Triplicate $25 \mu 1$ reactions were performed in Qiagen Multiplex

144 Master Mix (Qiagen) and $0.1 \mu \mathrm{M}$ under the following conditions: $94^{\circ} \mathrm{C}$ ( $5 \mathrm{~min}$ ); 27 cycles of 94

$145{ }^{\circ} \mathrm{C}(30 \mathrm{sec}) 51^{\circ} \mathrm{C}(30 \mathrm{sec}), 72^{\circ} \mathrm{C}(30 \mathrm{sec}) ; 72{ }^{\circ} \mathrm{C}(10 \mathrm{~min})$. Amplification was verified by

146 visualisation on $1 \%$ agarose gels. Triplicate PCRs of each sample were pooled and cleaned with

147 the Agencourt AMPure XP magnetic bead system (Beckman Coulter). Nextera XT indexing and

148 sequencing adapters were added via PCR ( 8 cycles) following the manufacturer's instructions.

149 Sample libraries were quantified on the BioAnalyzer (Agilent Technologies) and QuBit (Quant-IT

150 dsDNA Broad Range Assay Kit; Invitrogen) and pooled in equimolar ratios. This pool of libraries

151 was purified on a $2 \%$ Agarose gel to remove any excess primer and sequenced at 8pM with $10 \%$

152 phiX on the Illumina MiSeq, 2 x 300bp paired end version 3 chemistry according to manufacturer

153 specifications. Sequence data determined are available under NCBI BioProject ID PRJNA532516.

155 Identification of Symbiodiniaceae genetic diversity

156

157 Raw sequences for each sample (i.e., pairs of demultiplexed fastq.gz files) were processed using

158 the SymPortal analytical framework (symportal.org) which is described in detail in (Hume et al.,

159 2019). Sequencing information was submitted to the SymPortal remote database and underwent

This article is protected by copyright. All rights reserved 
quality control including the removal of artefact and non-Symbiodiniaceae sequences. Following quality control, each of our samples were represented by an average of 16,000 ITS2 rDNA 162 sequences (range: 2,000-47,000). Symbiodiniaceae genera (formerly Symbiodinium clades; see 163 LaJeunesse et al., 2018) were identified as part of the SymPortal analysis through blast querying a 164 database containing representatives of each genus. Sub-generic ITS2 type profiles were designated 165 by SymPortal based on the presence and abundance of the ITS2 sequences in our samples and 166 within the SymPortal database. In brief, sets of sequences found to re-occur in multiple samples 167 were searched for algorithmically. This search operates on a principle whereby the probability that 168 a given set of ITS2 sequences found in a single coral sample is representative of a single 169 Symbiodiniaceae genotype increases with the number of samples that set of sequences is found in. 170 In this way, SymPortal differentiates between intra- and intergenomic sequence diversity within 171 samples. The individual sequences (referred to as 'defining intragenomic [sequence] variants'; 172 DIVs) making up these re-occurring sets were used to define the ITS2 type profiles. Genera and 173 type profiles at $<1 \%$ proportional abundance within samples were excluded from downstream 174 analyses.

175

176

\section{Data analysis}

178

179 Symbiodiniaceae genera were initially analysed using the complete dataset evaluating host 180 species, region, and season as potential drivers of symbiont community composition. These 181 variables were analysed as crossed factors in a permutational multivariate analysis of variance 182 (PERMANOVA) with colony included as a nested factor within the host species by region 183 interaction. The model was performed using the vegan package in $R$ (vegdist and adonis functions; 184 Oksanen et al., 2019) with Bray-Curtis dissimilarities of proportional abundance data which were 185 square-root transformed to increase the representation of rare taxa. Where significant model terms 186 contained more than two groups, subsequent pairwise tests were performed and $P$ values were 187 adjusted for multiple comparisons (false discovery rate procedure; pairwise.adonis wrapper 188 function; Martinez Arbizu, 2017). An additional PERMANOVA was performed on the Persian 189 Gulf data using the same model features as above to investigate variation in Symbiodiniaceae 190 genera among specific sites and time-points for C. microphthalma and P. daedalea. However, 191 Acropora downingi data were excluded due to low replication across factors. The effect of coral 
192 bleaching on Symbiodiniaceae associations was evaluated by comparing the prevalence of non-

193 dominant genera in bleached versus non-bleached colonies, relative to the dominant Cladocopium 194 (clade C). One-sample t-tests for the prevalence of Symbiodinium (clade A:C ratio) and

195 Durusdinium (clade D:C ratio) in bleached corals were performed against mean values for

196 unbleached colonies due to zero or near-zero variances in the latter group (t.test function). Data

197 were pooled across coral species (C. microphthalma and P. daedalea) and sites (Saadiyat and Ras

198 Ghanada), as the levels of these factors did not differ from one another during the bleaching event.

199 Symbiodiniaceae composition in bleached corals was further investigated to see whether there was

200 any relationship between the abundance of non-dominant Symbiodiniaceae genera and

201 reproductive output during bleaching recovery. Oogenesis in C. microphthalma and P. daedalea

202 commenced during or shortly after the bleaching event in September 2012 (see A. Bauman, Baird,

$203 \&$ Cavalcante, 2011) and mature eggs were counted in samples collected in April 2013 (Howells,

204 Ketchum, et al., 2016). Correlation between the abundance of Symbiodinium + Durusdinium

205 (clade A + D) and the number of eggs per polyp mesentery was tested separately for $C$.

206 microphthalma and P. daedalea (cor.test function).

207

208 Symbiodiniaceae ITS2 type profiles classified by SymPortal were analysed separately for

209 Cladocopium (C, $n=23$ ITS2 type profiles) and Durusdinium (D, $n=12$ ITS2 type profiles). To

210 verify ecological patterns observed among ITS2 type profiles, analyses were also performed on the

211 underlying ITS2 sequences in which proportional abundance was $\geq 1 \%$ within samples (C, $n=32$

212 sequences; D, $n=19$ sequences). No further analysis was undertaken of Symbiodinium (clade A)

213 which comprised only one unique ITS2 sequence at $\geq 1 \%$ abundance. PERMANOVAs were

214 performed on Bray-Curtis dissimilarities of square-root transformed data, as outlined above. Initial

215 models showed that there were no temporal effects on type profiles or sequences for either

216 Symbiodiniaceae genus. Consequently, subsequent models only included samples from the first

217 time-point in which all colonies were represented. Cladocopium analyses tested host species and

218 site as crossed factors across all colonies from the Persian Gulf. C. microphthalma colonies

219 hosting Cladocopium in the Oman Sea were also included in analyses. However, due to lack of

220 replication, a single $A$. downingi colony from Saadiyat and a single $P$. daedalea colony from the

221 Oman Sea were excluded. The effect of coral bleaching on Cladocopium associations was tested

222 separately for each host species (C. microphthalma and P. daedalea) with site (Saadiyat and Ras

223 Ghanada) included as a model factor comparing associations in bleached versus non-bleached

This article is protected by copyright. All rights reserved 
224 colonies. Additionally, the association between coral bleaching and the abundance of the C3gulf 225 ITS2 sequence variant of Cladocopium was evaluated with a two-sample t-test and accompanying 226 effect sizes (Cohen's $D$ ) were calculated with the $l s r$ package (cohensD function; Navarro, 2015). 227 Durusdinium analyses tested host species as a main factor across all colonies from the Oman Sea. 228 For A. downingi, host effects are confounded with site, as colonies were collected from a nearby 229 distinct site (Dibba) $13 \mathrm{~km}$ away from C. microphthalma and P. daedalea (Al Aqah). Due to the 230 limited spread of Durusdinium across host species and sites in the Persian Gulf, samples from this 231 region were excluded. Variation among Cladocopium sequences from the Persian Gulf and 232 Durusdinium sequences from the Oman Sea were visualised using principal coordinates analyses 233 of the dissimilarity matrices using the ape package (pcoa function; Paradis, Claude, \& Strimmer, 234 2019).

235

\section{Results}

242

243 Symbiodiniaceae genera

245 Associations with Symbiodiniaceae genera in the corals Acropora downingi, Cyphastrea 246 microphthalma, and Platygyra daedalea were most strongly affected by the region of origin $\left(\mathrm{R}^{2}=\right.$ 247 0.92, Table S2, Supporting Information). Colonies from the thermally extreme Persian Gulf were 248 dominated by Cladocopium (clade C, 99\%, $n=273$ ), while those from the milder Oman Sea were 249 dominated by Durusdinium (clade D, 100\%, n=99) (Fig. 2). Sequences belonging to additional 250 genera were detected in all colonies from each region during at least one sampling season (i.e. $25194 \%$ of genotyped samples, $n=372)$, but were usually at very low abundances $(<0.1 \%)$. Once an 252 abundance threshold of 1\% was applied, associations with multiple genera were retained in the 253 majority of Persian Gulf colonies $(66 \%, n=94)$, but only a minority of Oman Sea colonies $(24 \%$, $254 n=34)$. In the Persian Gulf, Cladocopium often co-occurred with low levels of Symbiodinium 255 (clade A) and/or Durusdinium in both C. microphthalma (78\% of colonies) and P. daedalea 
256 (66\%), and occasionally with Durusdinium in A. downingi (33\%) (Fig. 2). In the Oman Sea,

257 Durusdinium associations were sometimes accompanied by Cladocopium in C. microphthalma

258 (58\% of colonies), but additional symbiont genera were virtually absent in the other host species.

259

260 The higher diversity of Symbiodiniaceae genera in the Persian Gulf corals did not correspond with

261 sampling season. Despite exposure to extreme seasonal changes in temperature $\left(\Delta 16^{\circ} \mathrm{C}\right)$, no

262 consistent shifts were observed in the composition of symbiont genera in coral colonies (Fig. 2;

263 Table S2). The only significant seasonal effect was for C. microphthalma at Delma, where

264 Symbiodinium was detected (in two colonies) during only the first time-point. Additionally, no

265 seasonal effects were detected over smaller temperature changes $\left(\leq 11^{\circ} \mathrm{C}\right)$ in the Oman Sea

266 (PERMANOVA, pseudo- $F_{3,98}=0.31, P>0.05$ ). However, during the heatwave in 2012, there was

267 higher prevalence of Symbiodinium within bleached versus non-bleached colonies (Wilcox test, W

$268=228, P=0.04)$; as well as a non-significant tendency for higher levels of Durusdinium $(P>$

269 0.05). Either or both of these genera were present within most bleached colonies of $C$.

270 microphthalma $(61 \%, n=23)$ and P. daedalea $(61 \%, n=23)$, where Symbiodinium levels reached

271 up to $54 \%($ mean $=9 \%)$ and Durusdinium levels were up to $11 \%($ mean $=2 \%)($ Fig. 2$)$. In

272 contrast, among the few colonies which resisted bleaching $(\mathrm{Cm}=6 ; \mathrm{Pd}=1)$, none hosted

273 Symbiodinium and only two hosted low levels $(<4 \%)$ of Durusdinium. In the aftermath of

274 bleaching, the reproductive output of $P$. daedalea colonies declined (Howells, Ketchum, et al.,

$2752016)$ and was also weakly correlated with the composition of symbiont genera $\left(R=-0.37, P_{\text {one- }}\right.$

276 tailed $=0.047$; Fig. S1a). Egg numbers varied widely among bleached $P$. daedalea colonies that only

277 hosted Cladocopium around the onset of gametogenesis (Bauman et al. 2011), but declined in

278 colonies with a higher prevalence of Symbiodinium and Durusdinium. For C. microphthalma,

279 reproductive output was unaffected by bleaching (Howells, Ketchum, et al., 2016) or the

280 prevalence of symbiont genera (Fig. S1b).

281

This article is protected by copyright. All rights reserved 


\section{Symbiodiniaceae ITS2 type profiles and sequence composition}

283

284 Associations with the ITS2 type profiles identified by SymPortal (http://symportal.org/) were 285 highly structured by host species and site of origin (Table S3). In the Cladocopium (clade C) 286 dominated associations of the Persian Gulf, almost all type profiles (17 of 19, 89\%) were only 287 found in single host species ( $A$. downingi $=3$ of 4, C. microphthalma $=7$ of 9, P. daedalea $=7$ of 288 8) (Fig. 3; Table S3). These specific type profiles were also unique to individual sites (14 of 17, $28982 \%$ ) or two neighbouring sites ( 3 of 17, 18\%). Although Cladocopium was not dominant in the 290 Oman Sea, associations with C. microphthalma in this region were also comprised of type profiles 291 that were both host and site-specific (Fig. S3). Similarly, in the Durusdinium (clade D) dominated 292 associations of the Oman Sea, all type profiles ( 8 of $8,100 \%$ ) were unique to a single host species: 293 A. downingi (3), C. microphthalma (3), or P. daedalea (2) (Fig. 4). In contrast, in the background 294 associations in the Persian Gulf (Fig. S4), most Durusdinium type profiles were shared among host 295 species (7 of 10, 70\%) and sites (6 of 10, 60\%), and a single Symbiodinium (clade A) type profile 296 was shared among host species and sites.

298 The ITS2 rDNA sequences underlying SymPortal type profile classifications confirmed the 299 observed pattern of associations that were highly structured by host species and site (Fig. 5; Table 300 S4). Our dataset comprised numerous sequences ( $\geq 1 \%$ abundance) belonging to Cladocopium 301 (32), Durusdinium (19), and Symbiodinium (1). ITS2 type profiles from within the same genus 302 (Cladocopium, Durusdinium) shared common major sequences and were distinguished by the 303 presence and identity of additional major (the most abundant defining intragenomic variants, 304 DIVs, of the type profiles found) and minor sequences (non-major DIVs; Table S1). Within 305 Cladocopium, C3 was the major sequence shared by the Persian Gulf type profiles in all host 306 species, while C15 was dominant in the Oman Sea type profiles in C. microphthalma. Consistent 307 with the SymPortal type profile classifications, 26 (81\%) of the minor Cladocopium ITS2 308 sequences were unique to individual host species (A. downingi $=1$ of 4, C. microphthalma $=15$ of $30921, P$. daedalea $=10$ of 16$)$, and $18(56 \%)$ were also unique to particular sites. Within 310 Durusdinium in the Oman Sea, D5 was the major ITS2 sequence in type profiles in A. downingi 311 and $P$. daedalea, while D1 and D17a were dominant in type profiles of C. microphthalma. Of the 312 minor Durusdinium sequences, 9 (47\%) only occurred in a single species (A. downingi $=3$ of 11 , 313 C. microphthalma $=3$ of 11, P. daedalea $=3$ of 13 ). 
315 Within the dominant Symbiodiniaceae genus hosted by individual coral colonies, ITS2 type

316 profile and sequence associations were generally stable over time (Fig. 3,4). Most colonies

317 sampled more than once over 19 months $(74 \%, n=116)$, hosted the same sub-generic type profile

318 with the same underlying ITS2 sequences. When temporal variation occurred, this was due to a

319 loss or gain of a minor sequence(s) prompting a shift in ITS2 type profile assignment. For

320 example, differences in the Cladocopium type profiles in $A$. downingi between the first two time

321 points (Fig. 3) reflect the loss or gain of $\mathrm{C} 115 \mathrm{~d}$ and $\mathrm{C} 3 \mathrm{~b}$, which were the least abundant sequences

322 within colonies (Table S1). There was no effect of bleaching on type profile associations in the

323 Persian Gulf, except for C. microphthalma at Ras Ghanada, where non-bleached colonies all

324 hosted the same type profile, while bleached colonies hosted one of several type profiles (Fig. 4;

325 Table S3). Similarly, there was no effect of bleaching on the community composition of

326 Cladocopium sequences (Table S4) or the total diversity of sequences within P. daedalea or $C$.

327 microphthalma hosts (ANOVA, $F_{1,46}=0.31, P>0.05$ ). However, when specific ITS2 sequences

328 were examined, bleaching resistance was strongly linked to the prevalence of the C3gulf variant.

329 On average, the abundance of the C3gulf sequence (relative to the total Cladocopium sequences)

330 was $29 \%$ higher in non-bleached $(0.195 \pm 0.016)$ versus bleached $(0.151 \pm 0.007)$ colonies $(t=$ -

3312.49 , Cohen's $D=0.95, P=0.03$; Table S5). Additionally, the abundance of C3gulf was higher

332 (by up to $>500 \%$ ) for all host species at the two warmest sites (Saadiyat and Ras Ghanada)

333 compared to the cooler site (Delma) within the Persian Gulf (Fig. S6).

\section{Discussion}

336

337 Our results demonstrate that Symbiodiniaceae communities in corals of the Arabian Peninsula

338 exhibit genetic structure that is greatest among regions, followed by host species and individual

339 sites. Previous studies have required the use of several molecular markers to resolve hierarchical

340 patterns of genetic diversity among Symbiodiniaceae genera, species, and populations (e.g. Finney

341 et al., 2010; Santos, Shearer, Hannes, \& Coffroth, 2004; Thornhill, Lewis, Wham, \& LaJeunesse,

342 2014). Here we show comparable levels of resolution using next-generation sequencing of the

343 multi-copy ITS2 marker and an analysis framework (SymPortal) that incorporates closely related

344 intragenomic variants (Hume et al., 2019). This approach overcomes the issue of evolutionarily 
345 relevant divergence at the ITS2 marker being obscured by a dominance of shared ancestral

346 sequences (Hume et al., 2019; Thornhill et al., 2014).

347

\section{Coral associations with Symbiodiniaceae genera}

349

350 We observed strong partitioning of Symbiodiniaceae genera between the southern Persian Gulf 351 and Oman Sea, which confirms the findings of recent studies (D'Angelo et al., 2015; Howells, 352 Abrego, et al., 2016; Ziegler et al., 2017). The dominance of Cladocopium (clade C) in the Persian 353 Gulf and Durusdinium (clade D) in the Oman Sea in Acropora downingi, Cyphastrea 354 microphthalma, Platygyra daedalea (Fig. 2) has also been documented in several other coral taxa 355 that acquire their symbionts from the environment (Ziegler et al., 2017). In contrast, the same 356 Symbiodiniaceae genus tends to occur in both regions in coral hosts that maternally inherit their 357 symbionts; for example, Cladocopium in Porites, Durusdinium in Pocillopora, and Symbiodinium 358 (clade A) in Stylophora (Ziegler et al., 2017). However, in these instances, partitioning may be 359 apparent at a finer sub-generic level (Hume, D'Angelo, Burt, \& Wiedenmann, 2018). For example, 360 Cladocopium in Porites predominantly belong to the C3 (C. thermophilum) group in the Persian 361 Gulf and the C15 group in the Oman Sea (D'Angelo et al., 2015). Similarly, the occasional 362 Cladocopium symbionts observed in C. microphthalma in the Oman Sea also belonged to the C15 363 group. Physiological experiments indicate that this consistent regional Symbiodiniaceae 364 divergence across coral hosts is driven by differential tolerance to temperature and salinity, with 365 specialisation of the $C$. thermophilum group to the more extreme conditions of the Persian Gulf 366 (D'Angelo et al., 2015; Howells, Abrego, et al., 2016).

368 Background (i.e., non-dominant) Symbiodiniaceae genera were more frequently observed in corals 369 from the Persian Gulf, than in the Oman Sea. The occurrence of Symbiodinium and/or 370 Durusdinium in combination with the dominant Cladocopium in the Gulf indicates that the 371 potential for changes in symbiont community composition is not limited by a lack of diversity in 372 this extreme environment (see also Hume et al., 2015; Smith, Vaughan, Ketchum, McParland, \& 373 Burt, 2017). Numerous studies have shown a greater prevalence of Symbiodinium and 374 Durusdinium in health-compromised corals in both the Western Pacific and Caribbean. Increases 375 in the abundance of Symbiodinium and Durusdinium have been observed in colonies during and 376 after bleaching (heat- and light-induced; Baker, 2001; Jones et al., 2008; Thornhill et al., 2006; 
377 Toller, Rowan, \& Knowlton, 2001) and in colonies suffering from disease (Rouzé, Lecellier,

378 Saulnier, \& Berteaux-Lecellier, 2016; Stat, Morris, \& Gates, 2008; Toller et al., 2001). Certain

379 genotypes of these genera presumably displace resident dominant symbionts under adverse

380 conditions due to their comparatively high stress tolerance (LaJeunesse, Smith, Finney, \&

381 Oxenford, 2009; Stat et al., 2008). In response to heat stress, shifts to Durusdinium dominance can

382 enable colonies to survive and resist subsequent bleaching (Berkelmans \& van Oppen, 2006;

383 Silverstein et al., 2015), although the majority of these cases may be limited to a relatively small

384 number of taxa (i.e., D. trenchii, (LaJeunesse et al., 2014). However, typical resident

385 Symbiodiniaceae taxa eventually re-establish dominance following the return of normal conditions

386 (e.g. LaJeunesse et al., 2009; Thornhill et al., 2006; Toller et al., 2001). The transient nature of

387 certain associations with Symbiodinium and Durusdinium genotypes is likely driven by the low

388 rates of photosynthetically fixed carbon transferred to hosts relative to their typical Cladocopium

389 and Breviolum residents (Cantin et al., 2009; Cunning, Silverstein, et al., 2015; Stat et al., 2008),

390 which negatively impacts coral growth and reproduction (Jones \& Berkelmans, 2011; Little et al.,

391 2004; Mieog et al., 2009).

392

393 In our study, the prevalence of Symbiodinium and Durusdinium was highest in bleached colonies

394 during the 2012 heatwave, particularly at Ras Ghanada (colony abundance up to 54\%; Fig 2). In

395 the following summer, a high prevalence of Symbiodinium was also observed in C. microphthalma

396 at Ras Ghanada (up to 36\%). While these colonies were normally pigmented at the time of

397 sampling, they may have experienced paling early in the summer when temperatures exceeded the

398 local bleaching threshold $\left(34.5^{\circ} \mathrm{C}\right)$ for 14 days (Fig. 1b). In both of these instances, the increased

399 prevalence of Symbiodinium and Durusdinium could be due to opportunistic proliferation of these

400 genera and/or the selective loss of the dominant Cladocopium during heat stress. While we cannot

401 distinguish between these possibilities, the absence of Symbiodinium and Durusdinium in the few

402 colonies that resisted bleaching suggests that proliferation is a more likely explanation. The

403 negative association of Symbiodinium and Durusdinium abundance with fecundity in P. daedalea

404 colonies (Fig. S1) further suggests that genotypes of these genera may also be opportunists in the

405 Persian Gulf. However, further physiological and energetic data are required to support this

406 interpretation. For instance, Gulf genotypes of Symbiodinium and Durusdinium are likely to be

407 heat tolerant (given their appearance at the warmest sampling times), but it is unknown whether

408 they remain non-preferred symbionts because they also exhibit inferior carbon transfer or whether

This article is protected by copyright. All rights reserved 
409 they suffer disproportionate stress under hypersalinity ( 2 PSU higher in winter) and/or winter

410 minimums $\left(<20^{\circ} \mathrm{C}\right)$.

411

412 Coral associations with Symbiodiniaceae ITS2 type profiles and intragenomic variants

413

414 Within both the Persian Gulf and the Oman Sea, colonies of A. downingi, C. microphthalma, $P$.

415 daedalea hosted unique type profiles and sequences of Cladocopium and Durusdinium (Figs. 3-5).

416 While coral species shared identical dominant ITS2 sequences (C3 in the Persian Gulf and D5 or

417 D1 in the Oman Sea), the majority of lower abundance intragenomic variants were unique to each

418 coral species. This finding demonstrates that the fine-scale symbiont specificity initially observed

419 among these coral species (Smith, Ketchum, \& Burt, 2017) extends across sites and regional

420 divisions in Symbiodiniaceae genera. Similarly, several coral species host unique variants of

421 common ITS2 types in the Caribbean (Cladocopium C3, Breviolum B1: Finney et al., 2010;

422 Santos et al., 2004; Thornhill et al., 2014) and Western Pacific (Cladocopium C3 and C40; Davies,

423 Wham, Kanke, \& Matz, 2019) that were previously viewed as "generalist" symbiont taxa (e.g.

424 LaJeunesse et al., 2003). As in these examples, the sympatric divergence of closely related

425 Symbiodiniaceae in the northeastern Arabian Peninsula indicates the specialisation of symbionts

426 to distinct host microenvironments. The fidelity of these partnerships, maintained by recognition

427 and winnowing mechanisms (Fransolet, Roberty, \& Plumier, 2012), results in reproductive

428 isolation, and ultimately speciation (Finney et al., 2010; Thornhill et al., 2014). Investigations of

429 fine-scale genetic variation are lacking from Indo-Pacific beyond the Arabian Peninsula (but see

430 Davies et al., 2019), and are required to re-evaluate the generalist nature of ITS2 lineages that are

431 common to many host species. However, it is likely that species-level diversity within the

432 Symbiodiniaceae is currently underestimated.

433

434 For each host species, we observed further spatial structuring of Cladocopium sequences in the

435 Persian Gulf. Genetic dissimilarity corresponded with oceanographic distance, where the

436 composition of ITS2 sequences was distinct between the nearby sites of Saadiyat and Ras

437 Ghanada (39 km apart) and most dissimilar from the isolated site of Delma (219-248 km away)

438 (Fig. 5). This fine scale spatial genetic structure is consistent with patterns observed with

439 microsatellite markers for Cladocopium populations on the Great Barrier Reef (Howells, van

440 Oppen, \& Willis, 2009; Howells, Willis, Bay, \& Oppen, 2013) and in the Caribbean (Thornhill et

This article is protected by copyright. All rights reserved 
442 differentiated due to limited dispersal and recruitment among sites and predominant asexual

443 reproduction within sites (Thornhill, Howells, Wham, Steury, \& Santos, 2017). An alternative

444 explanation is that site-specific sequences and type profiles represent functionally distinct

445 genotypes of Symbiodiniaceae that are adapted to local environmental conditions. Adaptation of

446 Symbiodiniaceae populations to local temperatures has been documented (Howells et al., 2012;

447 Pettay \& LaJeunesse, 2013), and our sites lie on an east-west gradient in temperature, salinity,

448 irradiance and primary productivity (Howells et al., 2018). However, this interpretation is

449 considered less likely, as environmental and coral community differences between Saadiyat and

450 Ras Ghanada remain very small (e.g. $\leq 0.5^{\circ} \mathrm{C}$ in mean, maximum and minimum temperature; and

$451 \leq 0.3 \mathrm{psu}$ in salinity). A more detailed study is required to fully elucidate Cladocopium population

452 genetic structure in the Persian Gulf, ideally incorporating a larger number of sites, and comparing

453 ITS2 intragenomic variation with population genetic markers (i.e., microsatellites or single

454 nucleotide polymorphisms).

455

456 The only Cladocopium ITS2 sequences common to every coral sample in the Persian Gulf were

457 the pantropical C3 variant and regional C3gulf variant diagnostic of the C. thermophilum group

458 (Hume et al., 2015; Hume et al., 2016). Molecular evidence indicates that the prevalence of this

459 stress tolerant group in the southern Gulf has arisen from positive selection acting on rare

460 widespread ancestral variation (Hume et al., 2016). Intriguingly, the variable abundance of C3gulf

461 we observed among samples (2 to $31 \%$ of total Cladocopium sequences) was highest at the

462 warmest sites and in the small number of colonies that resisted bleaching during the 2012

463 heatwave (7 unbleached versus 46 bleached colonies; Fig. S5, S6). This suggests that ITS2

464 intragenomic variation could reflect functional variation within Cladocopium populations. In

465 purely clonal populations, each individual cell would be expected to comprise a mixture of

466 intragenomic variants in equal proportions. However, infrequent recombination (Thornhill et al.,

467 2017) and/or somatic mutations (van Oppen, Souter, Howells, Heyward, \& Berkelmans, 2011)

468 could result in unequal proportions of intragenomic variants across offspring generations

469 (Wilkinson, Fisher, van Oppen, \& Davy, 2015). For example, the co-occurrence of C3 and C3gulf

470 may represent recombination between distinct lineages, with functional differences among

471 purebred, hybrid, and backcross generations (Wilkinson et al., 2015). In support of this

472 interpretation, Wilkinson et al. (2015) documented unequal proportions of ITS2 intragenomic

This article is protected by copyright. All rights reserved 
473 variants among Cladocopium cells that were consistent with recombination in colonies of

474 Pocillopora damicornis from subtropical Eastern Australia. Furthermore, the physiological

475 performance of Cladocopium in these coral colonies corresponded to the intragenomic status of

476 individual cells (i.e., homogenous vs heterogeneous ITS2 sequences; Wilkinson, Brian, Pontasch,

477 Fisher, \& Davy, 2018), and spatial differences in the abundance of intragenomically variable cells

478 was associated with a thermal gradient (Wilkinson, Pontasch, Fisher, \& Davy, 2016). For

479 Cladocopium populations from the Persian Gulf, verifying a role of intragenomic variation in 480 thermal tolerance requires targeted single-celled genotyping and physiological assays that were

481 beyond the scope of this study.

482

483 Coral symbiosis fidelity and climate warming

484

485 The Symbiodiniaceae communities in colonies of $A$. downingi, C. microphthalma, and $P$.

486 daedalea in the Persian Gulf and Oman Sea remained dominated by the same symbiont genus,

487 type profile, and intragenomic variants over the 1.5 years of this study. This strong fidelity is

488 despite exposure to extreme and seasonally variable temperatures, as well as the elimination and

489 repopulation of symbionts during bleaching. Clearly resident symbionts have an exceptional

490 capacity for thermal acclimation which encompasses both thermal extremes $\left(>32-34^{\circ} \mathrm{C}\right)$ and large

491 seasonal changes $\left(\Delta 11-16^{\circ} \mathrm{C}\right)$.

492

493 In the hottest reefs in the southern Gulf, it is unclear whether fidelity prevails because corals have 494 already established symbioses with the most tolerant taxa (i.e., the C. thermophilum group) or 495 whether alternatives (e.g. regional strains of Symbiodinium and Durusdinium) are sub-optimal 496 mutualists. The predominant differentiation of Cladocopium variants by sympatric host species 497 indicates that selection acts on the coral holobiont to drive mutualistic co-evolution (Laine, 2009).

498 Thus, adaptive responses of symbiont communities to climate warming are conceivably more 499 likely to occur within resident Symbiodiniaceae species (Howells et al., 2012) than by exchange of 500 species and genera. Recent studies show that Symbiodiniaceae populations do exhibit functional 501 variation and thus have the potential to adapt. For example, populations of two Breviolum B1 502 species (B. antillogorgium and B. minutum) from the same host species and reef site encompass 503 standing genetic variation in heat and nutrient tolerance, as well as photosynthesis traits (Bayliss, 504 Scott, Coffroth, \& terHorst, 2019). Additionally, a monoclonal culture of Cladocopium C1

This article is protected by copyright. All rights reserved 
505 adapted to elevated temperature within 2.5 years ( $~ 80$ asexual generations) and tended to improve 506 the outcomes for inoculated coral hosts under heat stress (Chakravarti, Beltran, \& van Oppen, 507 2017; see also Chakravarti \& van Oppen, 2018). While contemporary adaptation in natural 508 Symbiodiniaceae populations remains to be demonstrated, fidelity for specific symbiont partners 509 (i.e., putative species) does not negate the capacity for a symbiont role in coral adaptation. 510

514 Acknowledgements

515

516 The Environment Agency Abu Dhabi, Fujairah Municipality, and Dibba Municipality in the UAE 517 provided coral sampling permissions. Fieldwork was undertaken with the New York University 518 Abu Dhabi Core Research Vessel with additional support from The Palms Dive Center and Al 519 Mahara Dive Center. Sequencing was undertaken at the KAUST BioScience Core Lab. Craig 520 Michell prepared sequencing libraries and Dain McParland and Yasmin Mustafa assisted with 521 DNA extractions. The work was funded by New York University Abu Dhabi (JAB) and King 522 Abdullah University of Science and Technology (CRV). The authors declare that there are no 523 competing financial interests in the design and interpretation of this study.

\section{Authors contributions}

527 EJH and AGB conceived the study and CRV designed the molecular approach. EJH, AGB and 528 GOV performed fieldwork. EJH performed molecular work and BCCH and EJH analysed the 529 data. JAB and CRV provided funding and logistical support. EJH wrote the manuscript with initial 530 revisions from $\mathrm{BCCH}$ and $\mathrm{CRV}$, and final revisions from all authors.

\section{References}

533 
534 Aranda, M., Li, Y., Liew, Y. J., Baumgarten, S., Simakov, O., Wilson, M. C., . . Bajic, V. B.

537 Arif, C., Daniels, C., Bayer, T., Banguera-Hinestroza, E., Barbrook, A., Howe, C. J., ... Voolstra, (2016). Genomes of coral dinoflagellate symbionts highlight evolutionary adaptations conducive to a symbiotic lifestyle. Scientific reports, 6, 39734.

538

539 C. R. (2014). Assessing Symbiodinium diversity in scleractinian corals via next-generation sequencing-based genotyping of the ITS2 rDNA region. Molecular Ecology, 23(17), 4418-

541 Ateweberhan, M., McClanahan, T., Graham, N., \& Sheppard, C. (2011). Episodic heterogeneous 542

543 Baird, A. H., \& Marshall, P. A. (2002). Mortality, growth and reproduction in scleractinian corals 544 following bleaching on the Great Barrier Reef. Marine Ecology Progress Series, 237, 133141.

Baker, A. C. (2001). Reef corals bleach to survive change. Nature, 411(6839), 765-766.

Barshis, D. J. (2015). Genomic Potential for Coral Survival of Climate Change. In Coral Reefs in the Anthropocene (pp. 133-146): Springer.

Bauman, A., Baird, A., \& Cavalcante, G. (2011). Coral reproduction in the world's warmest reefs: southern Persian Gulf (Dubai, United Arab Emirates). Coral Reefs, 30(2), 405-413.

Bauman, A. G., Feary, D. A., Heron, S. F., Pratchett, M. S., \& Burt, J. A. (2013). Multiple environmental factors influence the spatial distribution and structure of reef communities in the northeastern Arabian Peninsula. Marine Pollution Bulletin, 72(2), 302-312.

Bayliss, S. L., Scott, Z. R., Coffroth, M. A., \& terHorst, C. P. (2019). Genetic variation in 5 Breviolum antillogorgium, a coral reef symbiont, in response to temperature and nutrients. Ecology and Evolution, 9(5), 2803-2813

Berkelmans, R., \& van Oppen, M. J. H. (2006). The role of zooxanthellae in the thermal tolerance 8 of corals: a 'nugget of hope' for coral reefs in an era of climate change. Proceedings of the Royal Society B-Biological Sciences, 273(1599), 2305-2312. doi:10.1098/rspb.2006.3567

0 Boulotte, N. M., Dalton, S. J., Carroll, A. G., Harrison, P. L., Putnam, H. M., Peplow, L. M., \& 1 van Oppen, M. J. (2016). Exploring the Symbiodinium rare biosphere provides evidence for symbiont switching in reef-building corals. The ISME journal, 10(11), 2693.

Buddemeier, R. W., \& Fautin, D. G. (1993). Coral bleaching as an adaptive mechanism - a testable hyspothesis. Bioscience, 43(5), 320-326. 
565 Cantin, N. E., van Oppen, M. J. H., Willis, B. L., Mieog, J. C., \& Negri, A. P. (2009). Juvenile 566 corals can acquire more carbon from high-performance algal symbionts. Coral Reefs, $567 \quad 28(2), 405-414$. doi:10.1007/s00338-009-0478-8

568 Chakravarti, L. J., Beltran, V. H., \& van Oppen, M. J. (2017). Rapid thermal adaptation in 569 photosymbionts of reef-building corals. Global Change Biology, 23(11), 4675-4688.

570 Chakravarti, L. J. C., \& van Oppen, M. J. (2018). Experimental evolution in coral photosymbionts 571 as a tool to increase thermal tolerance. Frontiers in Marine Science, 5, 227.

572 Chen, C. A., Wang, J.-T., Fang, L. S., \& Yang, Y.-W. (2005). Fluctuating algal symbiont 573 communities in Acropora palifera (Scleractinia:Acroporidae) from Taiwan. Marine 574 Ecology Progress Series, 295, 113-121.

575 Coffroth, M. A., \& Santos, S. R. (2005). Genetic diversity of symbiotic dinoflagellates in the 576 genus Symbiodinium. Protist, 156(1), 19-34. doi:10.1016/j.protis.2005.02.004

577 Cohen, I., Dubinsky, Z., \& Erez, J. (2016). Light enhanced calcification in hermatypic corals: new $578 \quad$ insights from light spectral responses. Frontiers in Marine Science, 2, 122.

579 Collins, M., Knutti, R., Arblaster, J., Dufresne, J.-L., Fichefet, T., Friedlingstein, P., .. . Krinner, 580 G. (2013). Long-term climate change: projections, commitments and irreversibility. 581 Cumbo, V., Baird, A., \& Van Oppen, M. (2013). The promiscuous larvae: flexibility in the 582 establishment of symbiosis in corals. Coral Reefs, 32(1), 111-120.

583 Cunning, R., Silverstein, R. N., \& Baker, A. C. (2015). Investigating the causes and consequences 584 of symbiont shuffling in a multi-partner reef coral symbiosis under environmental change. $585 \quad$ Proceedings of the Royal Society B: Biological Sciences, 282(1809), 20141725.

586 Cunning, R., Yost, D. M., Guarinello, M. L., Putnam, H. M., \& Gates, R. D. (2015). Variability of 587 Symbiodinium communities in waters, sediments, and corals of thermally distinct reef 588 pools in American Samoa. PLoS One, 10(12), e0145099.

589 D'Angelo, C., Hume, B. C., Burt, J., Smith, E. G., Achterberg, E. P., \& Wiedenmann, J. (2015). 590 Local adaptation constrains the distribution potential of heat-tolerant Symbiodinium from 591 the Persian/Arabian Gulf. The ISME journal.

592 Davies, S., Wham, D., Kanke, M., \& Matz, M. (2019). Contrasting population genetic structure in 593 Acropora coral hosts and their algal symbionts across multiple spatial scales. bioRxiv, 594 575183. 
595 Decelle, J., Carradec, Q., Pochon, X., Henry, N., Romac, S., Mahé, F., . . Wincker, P. (2018). Worldwide occurrence and activity of the reef-building coral symbiont symbiodinium in the open ocean. Current Biology, 28(22), 3625-3633. e3623.

598 Eakin, C. M., Morgan, J. A., Heron, S. F., Smith, T. B., Liu, G., Alvarez-Filip, L., . . Bouchon, C.

599 (2010). Caribbean corals in crisis: record thermal stress, bleaching, and mortality in 2005.

$600 \quad$ PLoS One, 5(11), e13969.

601 Finney, J. C., Pettay, D. T., Sampayo, E. M., Warner, M. E., Oxenford, H. A., \& LaJeunesse, T. C. 602 (2010). The relative significance of host-habitat, depth, and geography on the ecology, 603 endemism, and speciation of coral endosymbionts in the genus Symbiodinium. Microbial 604 ecology, 60(1), 250-263.

605 Fransolet, D., Roberty, S., \& Plumier, J.-C. (2012). Establishment of endosymbiosis: the case of 606 cnidarians and Symbiodinium. Journal of Experimental Marine Biology and Ecology, 420, $607-1-7$.

608 Gattuso, J.-P., Allemand, D., \& Frankignoulle, M. (1999). Photosynthesis and calcification at 609 cellular, organismal and community levels in coral reefs: a review on interactions and 610 control by carbonate chemistry. American Zoologist, 39(1), 160-183.

611 Goreau, T., \& Macfarlane, A. (1990). Reduced growth rate of Montastrea annularis following the 612 1987-1988 coral-bleaching event. Coral Reefs, 8(4), 211-215.

613 Howells, E. J., Abrego, D., Meyer, E., Kirk, N. L., \& Burt, J. A. (2016). Host adaptation and 614 unexpected symbiont partners enable reef-building corals to tolerate extreme temperatures. 615 Global Change Biology.

616 Howells, E. J., Beltran, V. H., Larsen, N. W., Bay, L. K., Willis, B. L., \& van Oppen, M. J. H. 617 (2012). Coral thermal tolerance shaped by local adaptation of photosymbionts. Nature $618 \quad$ Climate Change, 2, 116-120.

619 Howells, E. J., Dunshea, G., McParland, D., Vaughan, G. O., Heron, S. F., Pratchett, M. S., . . 620 Bauman, A. G. (2018). Species-specific coral calcification responses to the extreme 621 environment of the southern Persian Gulf. Frontiers in Marine Science, 5, 56.

622 Howells, E. J., Ketchum, R. N., Bauman, A. G., Mustafa, Y., Watkins, K. D., \& Burt, J. A. (2016). 623 Species-specific trends in the reproductive output of corals across environmental gradients and bleaching histories. Marine Pollution Bulletin, 105(2), 532-539. 
Howells, E. J., van Oppen, M. J. H., \& Willis, B. L. (2009). High genetic differentiation and crossshelf patterns of genetic diversity among Great Barrier Reef populations of Symbiodinium. Coral Reefs, 28(1), 215-225. doi:10.1007/s00338-008-0450-z

628 Howells, E. J., Willis, B. L., Bay, L. K., \& Oppen, M. J. (2013). Spatial and temporal genetic structure of Symbiodinium populations within a common reef-building coral on the Great Barrier Reef. Molecular Ecology, 22(14), 3693-3708.

631 Hughes, T. P., Anderson, K. D., Connolly, S. R., Heron, S. F., Kerry, J. T., Lough, J. M., .. . Bridge, T. C. (2018). Spatial and temporal patterns of mass bleaching of corals in the Anthropocene. Science, 359(6371), 80-83.

634 Hughes, T. P., Kerry, J. T., Baird, A. H., Connolly, S. R., Dietzel, A., Eakin, C. M., .. Liu, G. 635 (2018). Global warming transforms coral reef assemblages. Nature, 556(7702), 492.

636 Hume, B., D'Angelo, C., Smith, E., Stevens, J., Burt, J., \& Wiedenmann, J. (2015). Symbiodinium thermophilum sp. nov., a thermotolerant symbiotic alga prevalent in corals of the world's hottest sea, the Persian/Arabian Gulf. Scientific reports, 5.

Hume, B., Smith, E., Ziegler, M., Warrington, H., Burt, J., LaJeunesse, T., . . Voolstra, C. R. (2019). SymPortal: a novel analytical framework and platform for coral algal symbiont next-generation sequencing ITS 2 profiling. Molecular Ecology Resources.

642 Hume, B. C., D'Angelo, C., Burt, J. A., \& Wiedenmann, J. (2018). Fine-scale biogeographical boundary delineation and sub-population resolution in the Symbiodinium thermophilum coral symbiont group from the Persian/Arabian Gulf and Gulf of Oman. Frontiers in

646 Hume, B. C., Voolstra, C. R., Arif, C., D’Angelo, C., Burt, J. A., Eyal, G., . . Wiedenmann, J. (2016). Ancestral genetic diversity associated with the rapid spread of stress-tolerant coral symbionts in response to Holocene climate change. Proceedings of the National Academy of Sciences, 113(16), 4416-4421.

650 Jones, A. M., \& Berkelmans, R. (2011). Tradoffs to thermal acclimation: Energetics and reproduction of a reef coral with heat tolerant Symbiodinium type D. Journal of Marine Biology, Article ID 185890.

653 Jones, A. M., Berkelmans, R., van Oppen, M. J. H., Mieog, J. C., \& Sinclair, W. (2008). A 654 community change in the algal endosymbionts of a scleractinian coral following a natural bleaching event: field evidence of acclimatization. Proceedings of the Royal Society BBiological Sciences, 275(1641), 1359-1365. doi:10.1098/rspb.2008.0069 
Laine, A.-L. (2009). Role of coevolution in generating biological diversity: spatially divergent selection trajectories. Journal of experimental botany, 60(11), 2957-2970.

659 LaJeunesse, T. C. (2002). Diversity and community structure of symbiotic dinoflagellates from 660 Caribbean coral reefs. Marine Biology, 141(2), 387-400. doi:10.1007/s00227-002-0829-2 661 LaJeunesse, T. C., Loh, W. K. W., van Woesik, R., Hoegh-Guldberg, O., Schmidt, G. W., \& Fitt, 662 W. K. (2003). Low symbiont diversity in southern Great Barrier Reef corals, relative to 663 those of the Caribbean. Limnology and Oceanography, 48(5), 2046-2054.

664 LaJeunesse, T. C., Parkinson, J. E., Gabrielson, P. W., Jeong, H. J., Reimer, J. D., Voolstra, C. R., 665 \& Santos, S. R. (2018). Systematic revision of Symbiodiniaceae highlights the antiquity 666 and diversity of coral endosymbionts. Current Biology, 28(16), 2570-2580. e2576.

667 LaJeunesse, T. C., Smith, R. T., Finney, J., \& Oxenford, H. (2009). Outbreak and persistence of 668 opportunistic symbiotic dinoflagellates during the 2005 Caribbean mass coral 'bleaching' event. Proceedings of the Royal Society B-Biological Sciences, 276(1676), 4139-4148. 670 doi:10.1098/rspb.2009.1405

671 LaJeunesse, T. C., Wham, D. C., Pettay, D. T., Parkinson, J. E., Keshavmurthy, S., \& Chen, C. A. 672 (2014). Ecologically differentiated stress-tolerant endosymbionts in the dinoflagellate genus Symbiodinium (Dinophyceae) Clade D are different species. Phycologia, 53(4), $674 \quad 305-319$.

675 Lewis, C. L., Neely, K. L., Richardson, L. L., \& Rodriguez-Lanetty, M. (2017). Temporal 676 dynamics of black band disease affecting pillar coral (Dendrogyra cylindrus) following 677 two consecutive hyperthermal events on the Florida Reef Tract. Coral Reefs, 36(2), 427$678 \quad 431$.

679 Little, A. F., van Oppen, M. J. H., \& Willis, B. L. (2004). Flexibility in algal endosymbioses 680 shapes growth in reef corals. Science, 304(5676), 1492-1494.

681 Logan, C. A., Dunne, J. P., Eakin, C. M., \& Donner, S. D. (2014). Incorporating adaptive 682 responses into future projections of coral bleaching. Global Change Biology, 20(1), 125$683 \quad 139$.

684 Martinez Arbizu, P. (2017). pairwiseAdonis: Pairwise multilevel comparison using adonis. $R$ 685 package, https://github.com/pmartinezarbizu/pairwiseAdonis, 1 .

686 McGinley, M. P., Aschaffenburg, M. D., Pettay, D. T., Smith, R. T., LaJeunesse, T. C., \& Warner, 687 M. E. (2012). Symbiodinium spp. in colonies of eastern Pacific Pocillopora spp. are highly 
stable despite the prevalence of low-abundance background populations. Marine Ecology Progress Series, 462, 1-7.

690 Mieog, J. C., Olsen, J. L., Berkelmans, R., Bleuler-Martinez, S. A., Willis, B. L., \& van Oppen, M.

691 J. H. (2009). The Roles and Interactions of Symbiont, Host and Environment in Defining 692 Coral Fitness. PLoS One, 4(7), Article No.: e6364. doi::10.1371/journal.pone.0006364 693 Miller, J., Muller, E., Rogers, C., Waara, R., Atkinson, A., Whelan, K., . . Witcher, B. (2009). 694 Coral disease following massive bleaching in 2005 causes $60 \%$ decline in coral cover on 695 reefs in the US Virgin Islands. Coral Reefs, 28(4), 925.

696 Morrow, K., Muller, E., \& Lesser, M. (2018). How Does the Coral Microbiome Cause, Respond 697 to, or Modulate the Bleaching Process? In Coral Bleaching (pp. 153-188): Springer. 698 Muscatine, L., Falkowski, P., Porter, J., \& Dubinsky, Z. (1984). Fate of photosynthetic fixed 699 carbon in light-and shade-adapted colonies of the symbiotic coral Stylophora pistillata. 700 Proceedings of the Royal Society of London. Series B. Biological Sciences, 222(1227), 701 181-202.

702 Muscatine, L., R. McCloskey, L., \& E. Marian, R. (1981). Estimating the daily contribution of 703 carbon from zooxanthellae to coral animal respiration 1. Limnology and Oceanography, 704 26(4), 601-611.

705 Navarro, D. (2015). Companion to "Learning Statistics with R". https://cran.r706 project.org/web/packages/lsr/lsr.pdf.

707 Oakley, C., \& Davy, S. (2018). Cell Biology of Coral Bleaching. In Coral Bleaching (pp. 189708 211): Springer.

709 Oksanen, J., Blanchet, F. G., Kindt, R., Legendre, P., Minchin, P. R., O’hara, R., . . Wagner, H. 710 (2019). R package 'vegan'. https://cran.r-project.org/web/packages/vegan/vegan.pdf. 711 Paradis, E., Claude, J., \& Strimmer, K. (2019). R package 'ape', Analyses of Phylogenetics and 712 Evolution. https://cran.r-project.org/web/packages/ape/ape.pdf.

713 Pettay, D. T., \& LaJeunesse, T. C. (2013). Long-range dispersal and high-latitude environments 714 influence the population structure of a "stress-tolerant" dinoflagellate endosymbiont. PLoS $715 \quad$ One, 8(11), e79208.

716 Porter, J. W., Fitt, W. K., Spero, H. J., Rogers, C. S., \& White, M. W. (1989). Bleaching in reef 717 corals: physiological and stable isotopic responses. Proceedings of the National Academy 718 of Sciences, 86(23), 9342-9346. 
719 Putnam, H. M., Stat, M., Pochon, X., \& Gates, R. D. (2012). Endosymbiotic flexibility associates with environmental sensitivity in scleractinian corals. Proceedings of the Royal Society B: Biological Sciences. 279, 4352-61.

722 Quigley, K., Baker, A., Coffroth, M., Willis, B., \& van Oppen, M. (2018). Bleaching Resistance 723 and the Role of Algal Endosymbionts. In Coral Bleaching (pp. 111-151): Springer.

724 Quigley, K. M., Davies, S. W., Kenkel, C. D., Willis, B. L., Matz, M. V., \& Bay, L. K. (2014). 725 Deep-sequencing method for quantifying background abundances of Symbiodinium types: 726 exploring the rare Symbiodinium biosphere in reef-building corals. PLoS One, 9(4), 727 e94297.

728 Rädecker, N., Raina, J.-B., Pernice, M., Perna, G., Guagliardo, P., Kilburn, M. R., . . Voolstra, C. 729 R. (2018). Using Aiptasia as a model to study metabolic interactions in cnidarianSymbiodinium symbioses. Frontiers in physiology, 9, 214.

731 Riegl, B., Johnston, M., Purkis, S., Howells, E., Burt, J., Steiner, S. C., . . Bauman, A. (2018).

732 Population collapse dynamics in Acropora downingi, an Arabian/Persian Gulf ecosystem-engineering coral, linked to rising temperature. Global Change Biology, 24(6), 2447-2462.

735 Riegl, B. M., Purkis, S. J., Al-Cibahy, A. S., Abdel-Moati, M. A., \& Hoegh-Guldberg, O. (2011). 736 Present limits to heat-adaptability in corals and population-level responses to climate 738 Rouzé, H., Lecellier, G., Saulnier, D., \& Berteaux-Lecellier, V. (2016). Symbiodinium clades A 739 and D differentially predispose Acropora cytherea to disease and Vibrio spp. colonization. $740 \quad$ Ecology and Evolution, 6(2), 560-572.

741 Santos, S. R., Shearer, T. L., Hannes, A. R., \& Coffroth, M. A. (2004). Fine-scale diversity and 742 specificity in the most prevalent lineage of symbiotic dinoflagellates (Symbiodinium, Dinophyceae) of the Caribbean. Molecular Ecology, 13(2), 459-469. doi:10.1046/j.1365294X.2004.02058.X

745 Shuail, D., Wiedenmann, J., D'angelo, C., Baird, A. H., Pratchett, M. S., Riegl, B., . . Amos, C. 746 (2016). Local bleaching thresholds established by remote sensing techniques vary among reefs with deviating bleaching patterns during the 2012 event in the Arabian/Persian Gulf. Marine Pollution Bulletin, 105(2), 654-659. 
749 Silverstein, R. N., Cunning, R., \& Baker, A. C. (2015). Change in algal symbiont communities 750 after bleaching, not prior heat exposure, increases heat tolerance of reef corals. Global 751 Change Biology, 21(1), 236-249.

752 Smith, E., Vaughan, G., Ketchum, R., McParland, D., \& Burt, J. (2017). Symbiont community 753 stability through severe coral bleaching in a thermally extreme lagoon. Scientific reports, $7547(1), 2428$.

755 Smith, E. G., Ketchum, R. N., \& Burt, J. A. (2017). Host specificity of Symbiodinium variants 756 revealed by an ITS2 metahaplotype approach. The ISME journal, 11(6), 1500.

757 Stat, M., Loh, W. K. W., LaJeunesse, T. C., Hoegh-Guldberg, O., \& Carter, D. A. (2009). Stability 758 of coral-endosymbiont associations during and after a thermal stress event in the southern 759 Great Barrier Reef. Coral Reefs, 28(3), 709-713. doi::10.1007/s00338-009-0509-5

760 Stat, M., Morris, E., \& Gates, R. D. (2008). Functional diversity in coral-dinoflagellate symbiosis. 761 Proceedings of the National Academy of Sciences of the United States of America, 105(27), 762 9256-9261. doi:10.1073/pnas.0801328105

763 Suzuki, A., Gagan, M., Fabricius, K., Isdale, P., Yukino, I., \& Kawahata, H. (2003). Skeletal $764 \quad$ isotope microprofiles of growth perturbations in Porites corals during the 1997-1998 mass 765 bleaching event. Coral Reefs, 22(4), 357-369.

766 Swain, T. D., Chandler, J., Backman, V., \& Marcelino, L. (2017). Consensus thermotolerance 767 ranking for 110 Symbiodinium phylotypes: an exemplar utilization of a novel iterative 768 partial-rank aggregation tool with broad application potential. Functional ecology, 31(1), $769 \quad 172-183$.

770 Szmant, A., \& Gassman, N. (1990). The effects of prolonged "bleaching" on the tissue biomass 771 and reproduction of the reef coral Montastrea annularis. Coral Reefs, 8(4), 217-224.

772 Tchernov, D., Gorbunov, M. Y., de Vargas, C., Yadav, S. N., Milligan, A. J., Haggblom, M., \& 773 Falkowski, P. G. (2004). Membrane lipids of symbiotic algae are diagnostic of sensitivity to thermal bleaching in corals. Proceedings of the National Academy of Sciences of the 776 Thornhill, D., Howells, E., Wham, D., Steury, T., \& Santos, S. (2017). Population genetics of reef coral endosymbionts (Symbiodinium, Dinophyceae). Molecular Ecology, 26(10), 2640778 2659. 
779 Thornhill, D. J., LaJeunesse, T. C., Kemp, D. W., Fitt, W. K., \& Schmidt, G. W. (2006). Multi780 year, seasonal genotypic surveys of coral-algal symbioses reveal prevalent stability or post781 bleaching reversion. Marine Biology, 148(4), 711-722. doi:10.1007/s00227-005-0114-2

782 Thornhill, D. J., Lewis, A. M., Wham, D. C., \& LaJeunesse, T. C. (2014). Host-specialist lineages 783 dominate the adaptive radiation of reef coral endosymbionts. Evolution, 68(2), 352-367.

784 Toller, W. W., Rowan, R., \& Knowlton, N. (2001). Repopulation of zooxanthellae in the 785 Caribbean corals Montastraea annularis and $M$. faveolata following experimental and 786 disease-associated bleaching. Biological Bulletin (Woods Hole), 201(3), 360-373.

787 Torda, G., Donelson, J. M., Aranda, M., Barshis, D. J., Bay, L., Berumen, M. L., . . Matz, M. 788 (2017). Rapid adaptive responses to climate change in corals. Nature Climate Change, $789 \quad 7(9), 627$.

790 van Oppen, M. J. H., Souter, P., Howells, E. J., Heyward, A., \& Berkelmans, R. (2011). Novel 791 genetic diversity through somatic mutations: fuel for adaptation of reef corals? Diversity, 3, $792 \quad 405-423$.

793 Ward, S., Harrison, P., \& Hoegh-Guldberg, O. (2002). Coral bleaching reduces reproduction of $794 \quad$ scleractinian corals and increases susceptibility to future stress. Paper presented at the 795 Proceedings of the Ninth International Coral Reef Symposium, Bali, 23-27 October 2000. 796 Weis, V. M. (2008). Cellular mechanisms of Cnidarian bleaching: stress causes the collapse of 797 symbiosis. Journal of Experimental Biology, 211(19, Sp. Iss. SI), 3059-3066. 798 doi:10.1242/jeb.009597

799 Whitehead, L., \& Douglas, A. (2003). Metabolite comparisons and the identity of nutrients 800 translocated from symbiotic algae to an animal host. Journal of Experimental Biology, $801 \quad 206(18), 3149-3157$.

802 Wilkinson, S. P., Brian, J. I., Pontasch, S., Fisher, P. L., \& Davy, S. K. (2018). Intra-genomic 803 variation in Symbiodinium correlates negatively with photosynthetic efficiency and coral 804 host performance. Coral Reefs, 37(3), 691-701.

805 Wilkinson, S. P., Fisher, P. L., van Oppen, M. J., \& Davy, S. K. (2015). Intra-genomic variation in 806 symbiotic dinoflagellates: recent divergence or recombination between lineages? BMC 807 Evolutionary Biology, 15(1), 46.

808 Wilkinson, S. P., Pontasch, S., Fisher, P. L., \& Davy, S. K. (2016). The distribution of intra809 genomically variable dinoflagellate symbionts at Lord Howe Island, Australia. Coral 810 Reefs, 35(2), 565-576.

This article is protected by copyright. All rights reserved 
811 Ziegler, M., Arif, C., Burt, J. A., Dobretsov, S., Roder, C., LaJeunesse, T. C., \& Voolstra, C. R. 812 (2017). Biogeography and molecular diversity of coral symbionts in the genus 813 Symbiodinium around the Arabian Peninsula. Journal of Biogeography, 44(3), 674-686.

814 Ziegler, M., Eguíluz, V. M., Duarte, C. M., \& Voolstra, C. R. (2018). Rare symbionts may contribute to the resilience of coral-algal assemblages. The ISME journal, 12(1), 161.

816

817

818 Data availability

819

820 Raw sequencing data determined in this study are available under NCBI BioProject ID

821 PRJNA532516 (https://www.ncbi.nlm.nih.gov/bioproject/PRJNA532516). SymPortal source code 822 releases are published on the Zenodo platform (65).

823

824

825

826

827

828

829

830

831

832

833

834

835 Figure legends

836

837 Figure 1. The community composition of Symbiodiniaceae was tracked in the corals Acropora

838 downingi, Cyphastrea microphthalma, and Platygyra daedalea at five sites in the northeastern

839 Arabian Peninsula (a). Tissue samples were collected from tagged colonies at 5-7 month intervals,

840 at the end of two consecutive summers $(2012,2013)$ and winters $(2013,2014)$ (b). Sites

841 experienced seasonal temperature fluctuations between $10-11^{\circ} \mathrm{C}(\mathrm{Oman} \mathrm{Sea})$ and $16^{\circ} \mathrm{C}(\mathrm{Persian}$ 
842 Gulf) with summer maxima of $32-35^{\circ} \mathrm{C}$ and winter minima of $19-22^{\circ} \mathrm{C}$. Acute heat stress (coral

843 bleaching) occurred in 2012 at Saadiyat and Ras Ghanada when temperatures exceeded site-

844 specific bleaching thresholds $\left(34.5^{\circ} \mathrm{C}\right.$, Shuail et al. 2016 ; indicated by the dashed horizontal line).

845 Temperature data are daily means from loggers attached to the reef substrate (site gaps = missing

846 data). The base map was sourced from http://editor.openmaptiles.org.

848 Figure 2. The abundance of Symbiodiniaceae genera (clades) within tagged colonies of the corals 849 Acropora downingi (a), Cyphastrea microphthalma (b), and Platygyra daedalea (c) at sites within 850 the Persian Gulf (Delma, Saadiyat, Ras Ghanada) and Oman Sea (Dibba, Al Aqah). Individual 851 colonies, represented by horizontal bars, were sampled in September 2012, April 2013, September 852 2013, and February 2014 (b and c only). Symbols indicate colonies that were moderately bleached 853 (pale, circles) or severely bleached (white, triangles) during the first time point.

857 Figure 3. The abundance of Cladocopium (clade C) ITS2 type profiles within tagged colonies of 858 the corals Acropora downingi (a), Cyphastrea microphthalma (b), and Platygyra daedalea (c) at 859 sites within the Persian Gulf (Delma, Saadiyat, Ras Ghanada). Individual colonies, represented by 860 horizontal bars, were sampled in September 2012, April 2013, September 2013, and February 8612014 (b and c only). Symbols indicate colonies that were moderately bleached (pale, circles) and 862 severely bleached (white, triangles) during the first time point. Relationships among type profiles 863 are shown in Fig. S2. In contrast to the C3 dominated type profiles of the Persian Gulf, 864 Cladocopium associations in the Oman Sea (in C. microphthalma) were comprised of type profiles 865 belonging to C15 (Fig. S2, S3).

867 Figure 4. The abundance of Durusdinium (clade D) ITS2 type profiles within tagged colonies of 868 the corals Acropora downingi (a), Cyphastrea microphthalma (b), and Platygyra daedalea (c) at 869 sites within the Oman Sea (Dibba, Al Aqah). Individual colonies, represented by horizontal bars, 870 were sampled in September 2012, April 2013, September 2013, and February 2014 (b and c only).

871 Relationships among type profiles are shown in Fig. S2. Uncommon low-abundance associations 872 with Durusdinium in the Persian Gulf did not belong to divergent type profiles (Fig. S2, S4). 
874 Figure 5. Dissimilarity plot of Symbiodiniaceae ITS2 rDNA sequences belonging to Cladocopium 875 (clade C) (a) from the Persian Gulf, and (b) Durusdinium (clade D) from the Oman Sea. Sample 876 profiles (circles) differ by host coral species (Acropora downingi = green, Cyphastrea 877 microphthalma $=$ blue, Platygyra daedalea $=$ red) and reef site (colour shade). Principal 878 coordinates analysis was performed on the Bray-Curtis dissimilarities of square-root transformed 879 data of the proportional abundance of unique sequences within each genus. 


$\begin{array}{ll} & \text { Delma } \\ & \text { Saadiyat } \\ & \text { Ras Ghanada } \\ & \text { Dibba } \\ 100 \mathrm{~km} & \text { Al Aqah }\end{array}$

A Sample collection

Bleaching threshold

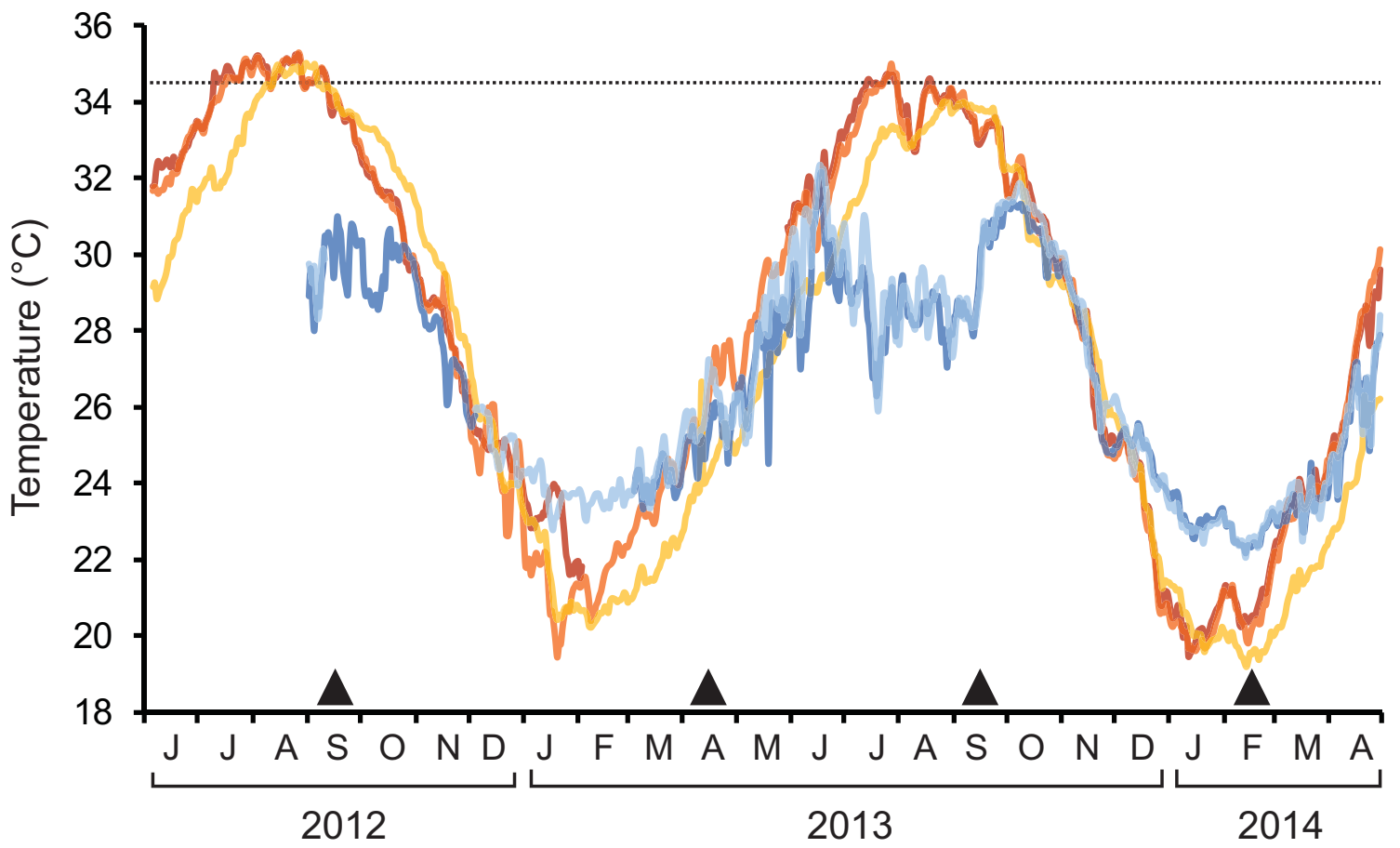



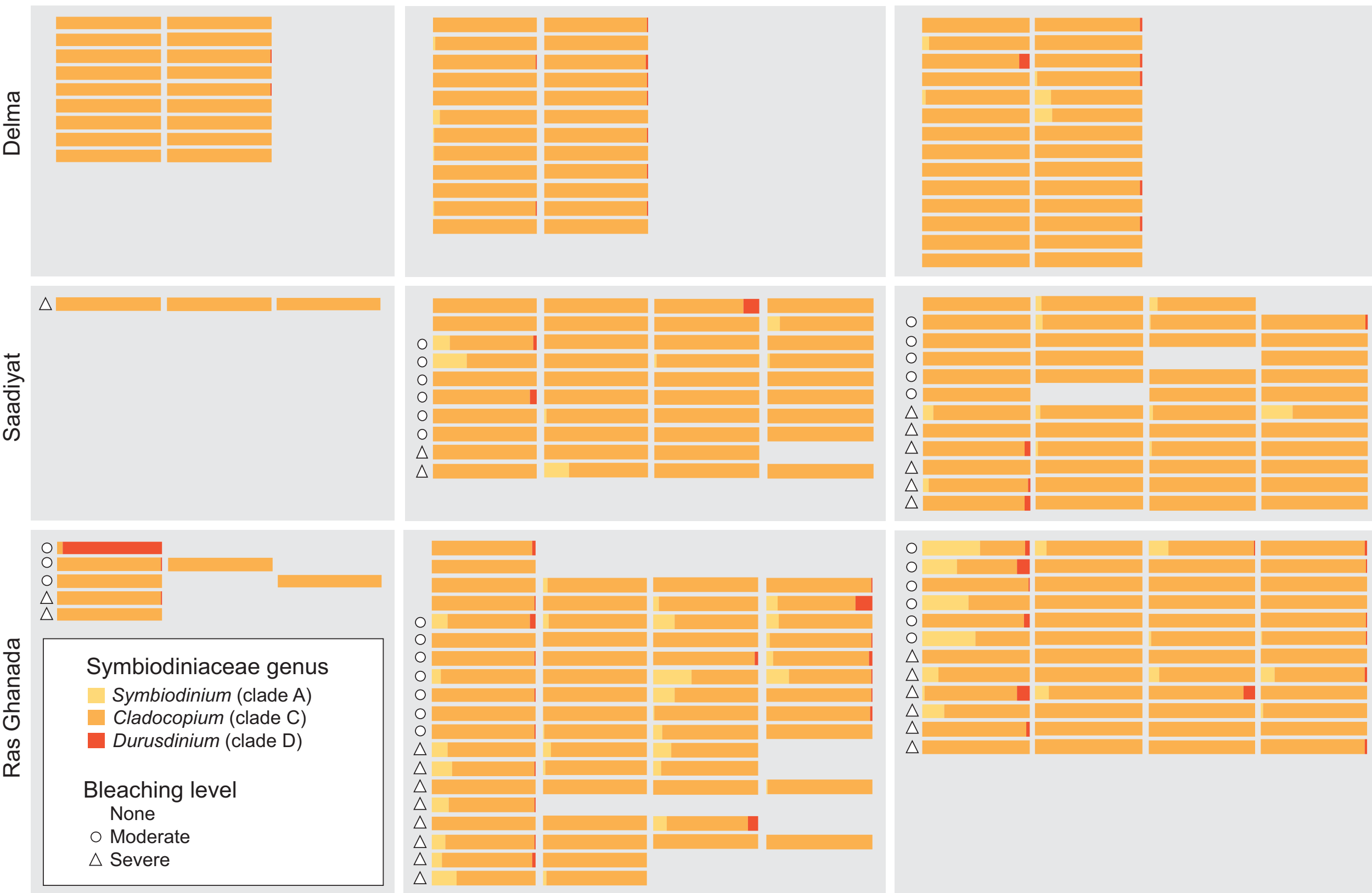
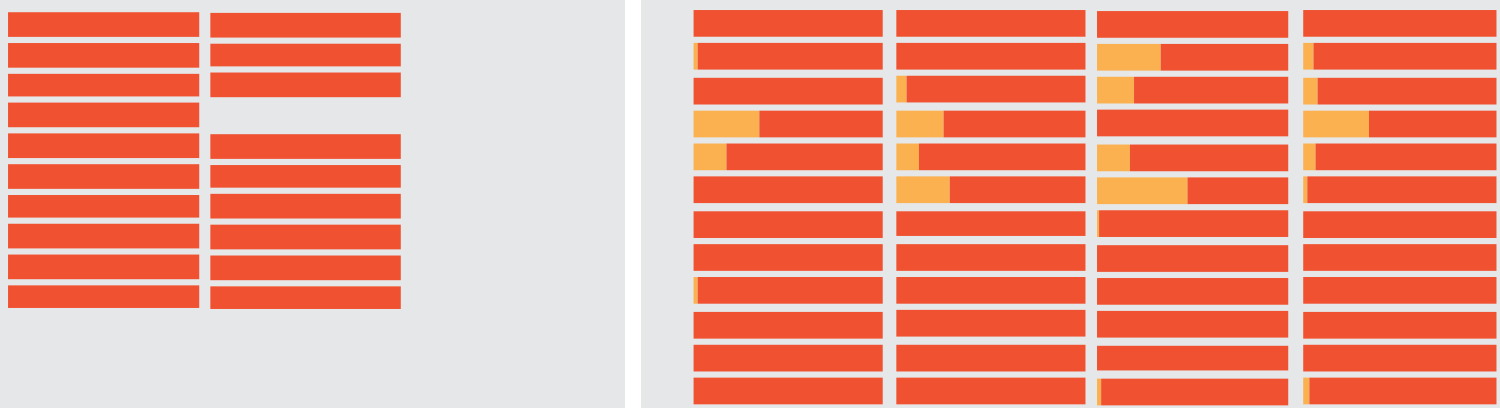

Sep. 2012 Apr. 2013
Sep. 2012
Sep. 2013
Feb. 2014

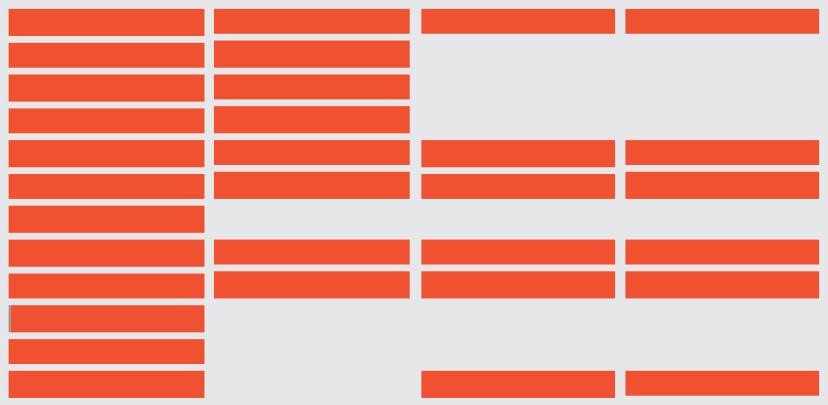

Sep. 2012 Apr. $2013 \quad$ Sep. 2013 Feb. 2014 

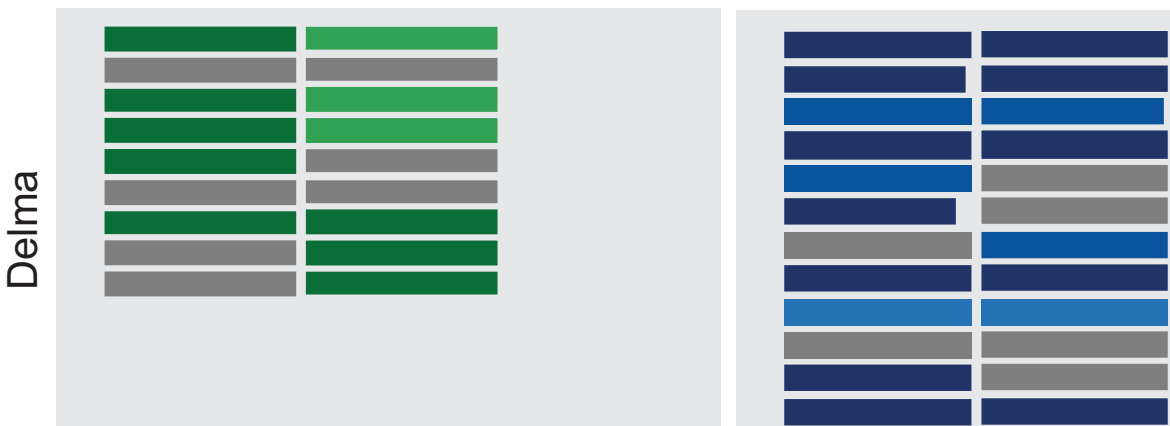

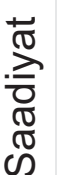
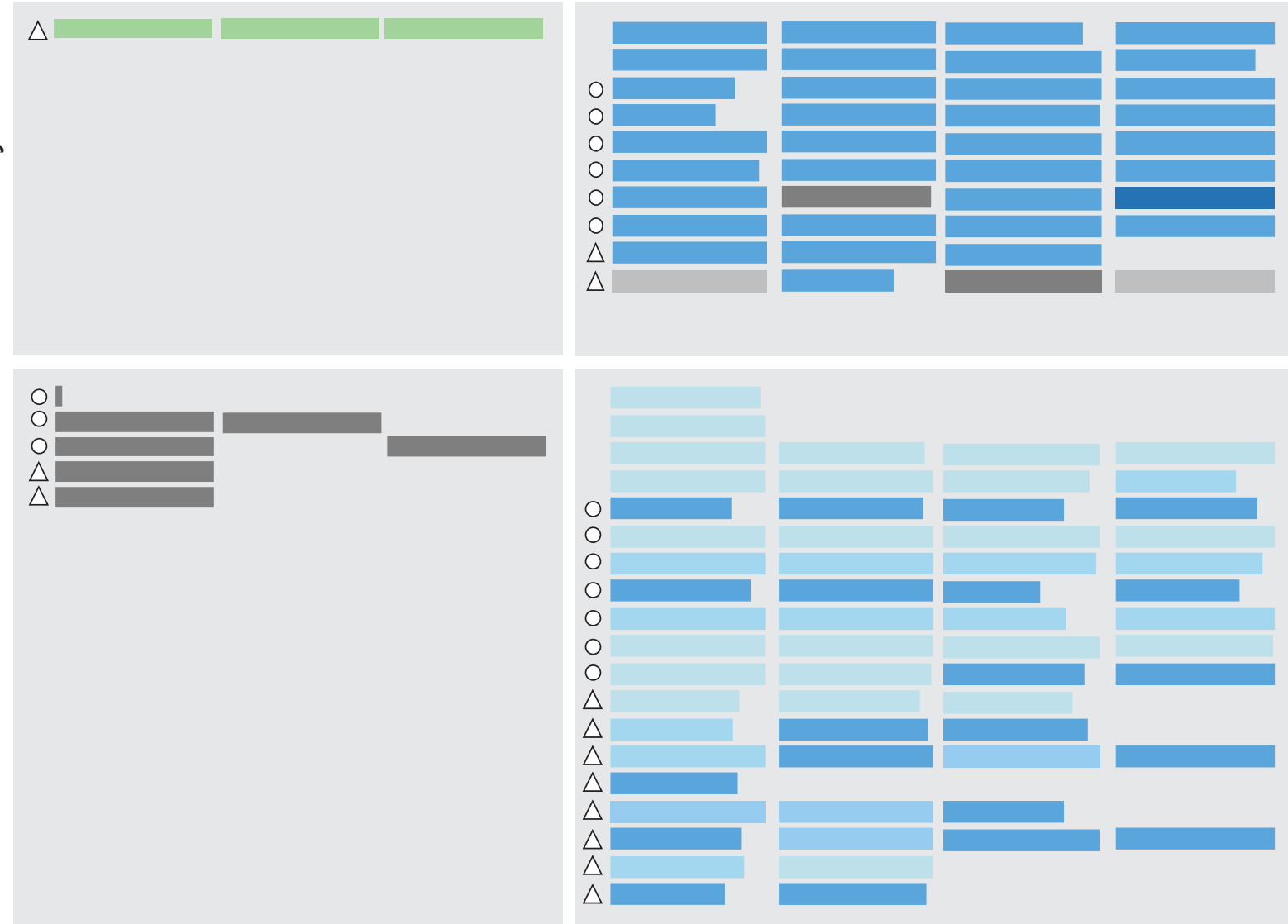
a Acropora downingi b Cyphastrea microphthalma

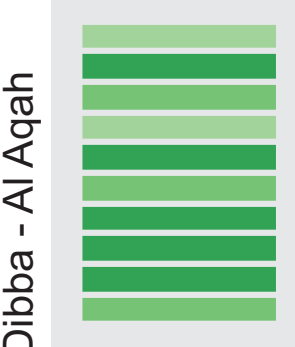

Sep. 2012
C Platygyra daedalea

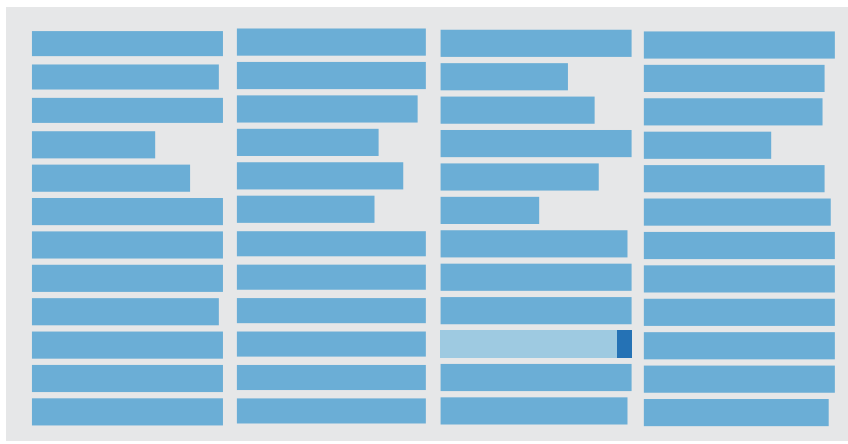

Sep. 2012 Apr. 2013 Sep. 2013 Feb. 2014

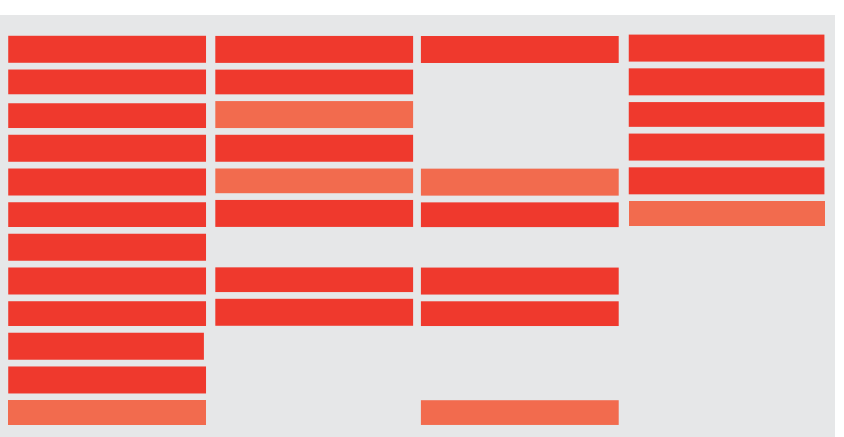

Sep. 2012 Apr. 2013 Sep. 2013 Feb. 2014
Durusdinium (clade D) type profile D5-D4-D4a-D2-D5d-D5g-D5h

D5-D5a-D4-D4a

D5-D4a-D4-D2-D5d

D17a

D1/D17a-D4-D17-D1g

D5/D1/D4-D5a

D5-D5a-D4-D5f-D4a

D5-D5c-D4a-D5b-D4-D5i 
a Persian Gulf Cladocopium (clade C)

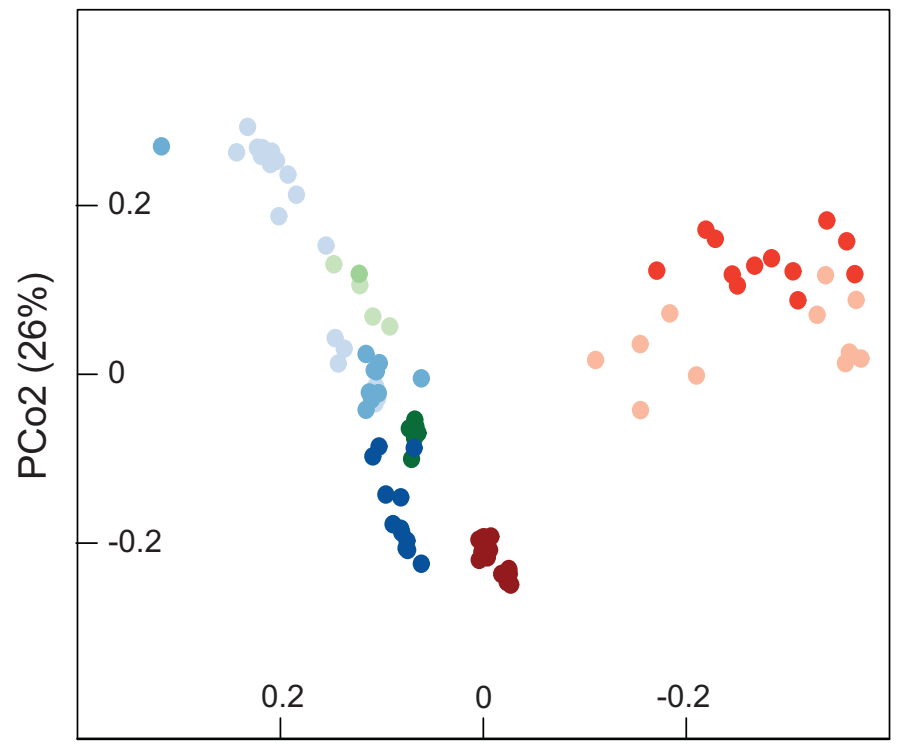

PCo1 (36\%) b Oman Sea Durusdinium (clade D)

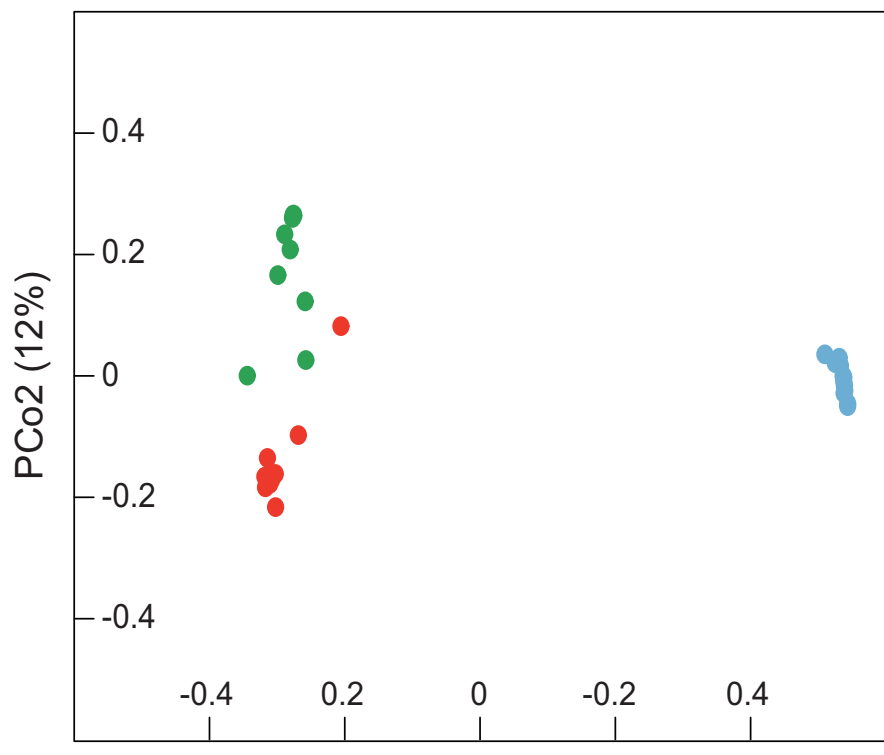

Acropora downing

- Dibba

Cyphastrea microphthalma

- Al Aqah

Platygyra daedalea

- Al Aqah
- Saadiyat

Ras Ghanada

Platygyra daedalea

- Delma

- Saadiyat

- Ras Ghanada

PCo1 (84\%) 